\title{
Thermoelectric Generator: A Source of Renewable Energy
}

\author{
Nicanor B. Fabracuer, Jr. ${ }^{1}$, Reymart A. Cepe ${ }^{2}$, Neil Francis S. Ricafort ${ }^{2}$, Rhoda Jane G. Rosal ${ }^{2}$ \\ ${ }^{1}$ Research and Publication Center, University of Mindanao, Matina Davao City, 8000 Philippines \\ ${ }^{2}$ College of Engineering Education, University of Mindanao, Matina Davao City, 8000 Philippines
}

Received 14 September 2019; Accepted 16 November 2019

Available online 28 February 2020

\begin{abstract}
With the natural sources of energy such as fossil fuels is slowly depleting, it became a trend to find new sources of unlimited energy. Renewable source of energy is the best source of unlimited energy for it will be utilizing the resources around like solar, hydro, wind, and many more. One of those newly developed renewable sources utilizes the waste heat developed by individual machines. Since electrical generating machines that use combustion engines generate a considerable amount of waste heat energy from the exhaust gases. Hence, this study focused on waste heat energy harvester by the use of the thermoelectric generator. Thermoelectric power generation is based on a phenomenon called the Seebeck effect. When a temperature difference is established between the hot and cold junctions of two dissimilar materials, a voltage is generated. The heat flow circulation through the semiconductors causes a displacement of charge carriers. A larger delta temperature creates a larger electrical current, ideally, but it is coupled with the fact that a semiconductor is effective only on a temperature range making the thermoelectric generators operational on a limited delta temperature. Primarily, the device was composed of a thermoelectric module mounted on an aluminum plate and placed in an oven. The main objective of the study is to design a circuitry for the thermoelectric generator that aimed to generate a minimum of 20 watts in order to power an AC load. In order to validate the device fabricated, certain measurements needed to be taken during the operation of the prototype. Thus, this device is now a developing source of alternative energy with further studies and innovations for commercial purposes.
\end{abstract}

Keywords: thermoelectric generator, Seebeck effect, semiconductors

\section{Introduction}

\subsection{Background of the Study}

Coal has been one of the major contributors to the energy supply in many countries and was the most widespread kind of fossil fuel around the world. In fact, there were more than 75 countries around the world that has coal deposits. Also, in the year 2013, the share of coal in the global power generation was more or less $40 \%$ but expected to decrease in succeeding years, while the coal consumption had been gradually increasing. China alone used as much coal as the other competing countries. And that was only in terms of coal. Other developed countries are slowly acknowledging the importance of using renewable energy. There are the top 11 countries that have been shifting to renewable energy. These leading countries have one common goal, and that is to eliminate or lessen the usage of fossil fuels in generating electricity.

The solution to the problems of climate change and energy insecurity demands large-scale conversion to clean, continual, and reliable energy at a low cost alongside of an increase in energy efficiency. Subsidies for renewable energy sources have been justified by the need to decarbonize the world economy. Decarbonization was thought to be necessary to control and limit carbon dioxide emissions. However, the strength of renewables lies in the diversity and the abundance of their technology options

\footnotetext{
* Corresponding author

E-mail address: nick_fabracuer@umindanao.edu.ph
} 
and applications, as well as their extensive availability. Renewables offer a large portfolio of different sources and technologies.

Thermoelectric Phenomenon. Thermoelectric effect is dependent on some governing factors. There are three physical phenomena of which are significant to the studies of thermoelectric devices: Peltier effect, Seebeck effect, and Thomson effect.

Peltier Effect. Later on in 1834 the reverse of the Seebeck effect was discovered by a French physicist, Jean Peltier, whereby heat would be absorbed and liberated at opposite ends in the same circuit of dissimilar metals when current (or a voltage potential) was present. The direction of current would determine the direction of heating or cooling. The proportionality of the rate of heat transfer to amount of current in the circuit was governed by the Peltier coefficient. Peltier effect where the direction of heat transfer into the circuit indicates heat absorbed and direction of heat transfer out of the circuit indicates heat liberated. This also dictates the sign convention of the Peltier coefficient making it positive for heat absorbed (entering the circuit) and negative for heat liberated (leaving the circuit). The Peltier effect is reversible between heat and electricity, meaning that the effects either of producing heat transfer from electricity or producing electricity from heat transfer are interchangeable without a loss of energy.

\subsection{Statement of the Problem}

The objective of the study was to generate power by utilizing the heat from the oven with the use of the thermoelectric generator specifically: a. to design a circuitry for the thermoelectric generator; $b$. to implement the use of a thermoelectric generator on an oven; c. to perform function tests in terms of the following: 1 . voltage output; 2 . current output; 3 . power output.

\subsection{Conceptual Framework}

This research is all about harvesting heat and utilizing it in order to produce electricity conceptualized with to work and survive under the condition such as intense heat without damaging the device since the proponents are working under intense heat from the oven. The one side of the thermoelectric module was placed on the hot side of the oven, and the other portion will have a cold side due to the water that will have a cycle to maintain the desired thermal difference to produce the target power output.

Figure 1 shows how the proponents came up with the idea of this study. The proponents designed the circuitry of the thermoelectric generator. After designing the circuitry, the flow for its cold and hot side were fabricated. And lastly, the output device was put on an oven in order to harvest waste energy and to generate electricity.

INPUT

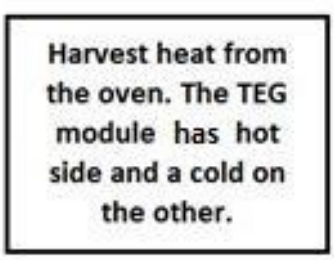

PROCESS

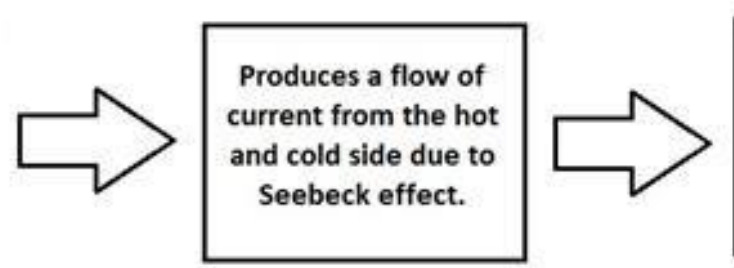

OUTPUT

Figure 1. Conceptual framework.

\subsection{Scope and Limitation}

This study was limited only to design and fabricate thermoelectric generator. The heat source to be used will be coming from the excess heat of the oven. The target output of the design is to generate at least 20 watts of power. The device is expected to have an AC output in order to power four 5-watt LED bulb. 


\section{Materials and Methods}

This section discussed the research methods available for the study and what was applicable for it to use. Likewise, this chapter would present the various procedures and strategies in identifying sources for needed information on the analysis and evaluation of the thermoelectric generator. Thus, this part of the study specifies the method of research used, research design, conceptual framework, research process, instruments used, trade-off analysis, and statistical treatment.

\subsection{Research Design}

In this research study, the method used is a capstone research. In this method, the proponents are encouraged to think critically, solve challenging problems, and develop skills such as research skills, teamwork, planning, self-sufficiency, and goal setting. Capstone projects involve identifying an information problem in a real-world setting and developing the means to address it. In capstone projects, solutions are typically interactive, meaning the end product is something that can be implemented and used. All the knowledge and skills of the proponents were being applied in designing this thermoelectric generator. This study provides all methods and data in order to ensure its functionality and durability in the long run. The thermoelectric modules were ensuring to handle varying thermal conditions of the oven. Since TEG produced DC electrical power, it was then inverted in order to power AC LED bulbs. Moreover, this study includes the actual application of collective scientific knowledge, including experiments, testing, analyzing, and realizing of the research within the time-bounds.

\subsection{Research Process}

The researchers have a procedure to follow in conducting the said study. It is a step-by-step process for planning and constructing the device and making sure that it follows the process to make the study efficient. The procedures are shown in Figure 2.

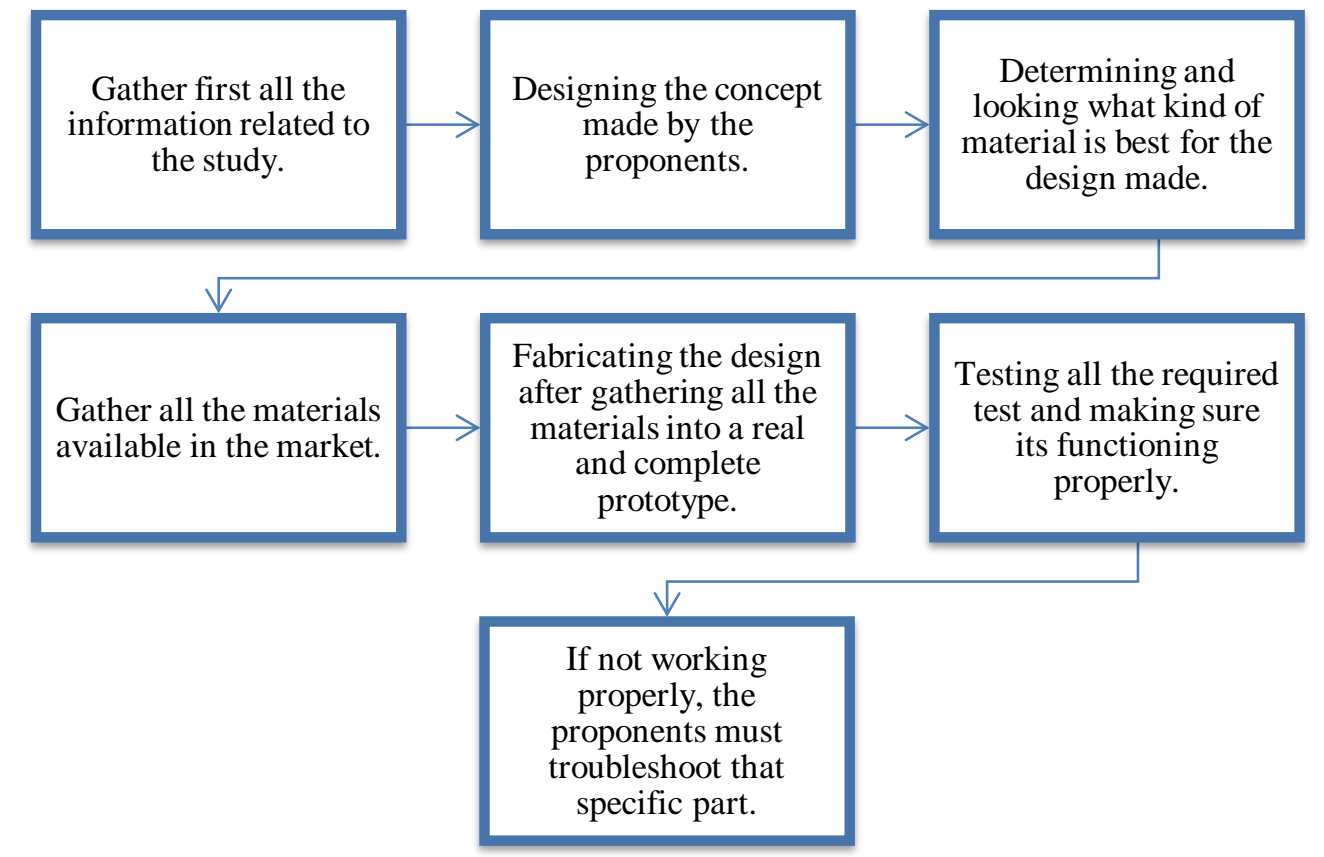

Figure 2. Research process flow.

Gathering Information. Every needed information related to the study should be collected and analyzed for a better understanding of the concept. It is only limited to a specific where the researchers must focus. 
Project Designing. The project should be designed in accordance with its proper framework. The project designing includes the circuitry of the whole device. The proponents decided that the TEG module will be placed above the oven along with the aluminum plate. The aluminum plate is a good conductor of heat, and it also has a fast cooling property. The proponents also decided what will be the best materials for each part that will use in making the said device.

Canvassing of Materials. All the information about the materials that was used for making the project should be gathered to get its necessary data. It includes its data sheet, manual, and the price for proper use and budgeting. The major material that will be use for the structure of the device is the Thermoelectric Generator. Then oven which is the source of the hot side for the TEG, the water pump and the water reservoir to be connected together for the cool side of the TEG.

Gathering of Materials. After the gathering of information of the materials for the use of the device, the researchers, now, should collect the necessary materials for constructing the device. The oven, which will be the body of the device, the TEG, on the top of the oven and the water reservoir besides the oven for the cool side.

Assembling the Device. All the materials needed for the device are now ready. Now, it's time for assembling the actual device used in the project. The proponents first made the structure of the TEG and the aluminum plate. Thermal paste was used to put together the TEG and the aluminum plate, the cool side on the top and the hot side on the bottom. The design of the cool side will be shown below. The upper part of the oven was cut-open, and the aluminum plate with the TEG inside was replaced on it. The TEG along the aluminum plate was bolted on the top of the oven. All of its components should be properly installed in the device such as the aluminum plate, so the heat from the oven will have a close circulation inside and no holes are made beside the aluminum plate. The hose for the cool side, which will where the water will flow is detachable connected to the water pump. The inverter along with the bulb will be connected after the TEG will reach its set value voltage where the TEG can now function.

Function Testing. After the constructing of the device, now, it should be tested for its functionality. Through these function testing, precise data is significant in order to determine if the study is conducted accurately. All materials that will be used in the study should be properly checked and tested for accurate functionality. The water on the cool side should circulate first before turning on the oven for the reason that there is a room temperature inside the oven. After a few minutes, turn the oven on a minimum heat and gradually increase it over time. When the multi-tester approach the set value voltage, the inverter will now be connected to supply the light bulb.

\section{Results and Discussion}

\subsection{Function Test Result}

Here, the proponents present all the data that were gathered and put all of it in table form from the functionality test according to what was needed in the objectives of the study. It will be followed by a discussion of the observation from the data accumulated by the researchers.

During the function test, the proponents would allot a minute of interval in order for the thermal difference between the cool and hot side of the generator to gradually increase.

For the first trial, as shown in Table 1, all the variables needed for this study, such as the hot and cold side temperatures, the voltage, and the current are accumulated. The minimum voltage and current outputs are 0.0304 volts and 0.02 amperes. The maximum voltage and current outputs are 21.21 volts and 0.63 ampere having the full power output of 12.09 watts. Based on the results obtained, the proponents did not reach the minimum desired power to be generated since the testing was done outside the laboratory where the air can affect the output since the oven had holes on the side in which when a wind will blow near or outside the oven, the heat tends to move around. Thus, the hot side temperature 
on each TEG module is not equal, that makes the TEG module act as a resistor in order to balance the output. The results also show that as the temperature difference increases, the voltage generated also increases.

Table 1. Actual output of TEG for Trial 1.

\begin{tabular}{|c|c|c|c|c|c|c|c|c|}
\hline TIME & T1 & $\mathbf{T} 2$ & $\Delta \mathbf{T}$ & V & I ACT & ITHEO & $\mathbf{P}$ & Error $(\%)$ \\
\hline 0 & 25.6 & 17 & 8.6 & 0.0304 & 0.02 & 0.033 & 0.001 & 39.39 \\
\hline 1 & 28.9 & 18.9 & 10 & 1.7 & 0.037 & 0.039 & 0.063 & 5.13 \\
\hline 2 & 111 & 18.7 & 92.3 & 9 & 0.304 & 0.36 & 2.736 & 15.56 \\
\hline 3 & 134 & 21 & 113 & 13.2 & 0.365 & 0.44 & 4.818 & 17.05 \\
\hline 4 & 137.6 & 20.9 & 116.7 & 14.6 & 0.4 & 0.45 & 5.840 & 11.11 \\
\hline 5 & 152.7 & 20.7 & 132 & 15.7 & 0.442 & 0.51 & 6.939 & 13.33 \\
\hline 6 & 134.4 & 21.9 & 112.5 & 16.4 & 0.482 & 0.43 & 7.905 & 12.09 \\
\hline 7 & 148.8 & 21.8 & 127 & 16.78 & 0.482 & 0.49 & 8.088 & 1.63 \\
\hline 8 & 134.8 & 22 & 112.8 & 17.28 & 0.48 & 0.44 & 8.294 & 9.09 \\
\hline 9 & 142 & 22.5 & 119.5 & 17.55 & 0.481 & 0.46 & 8.442 & 4.57 \\
\hline 10 & 158.9 & 22.4 & 136.5 & 17.98 & 0.5 & 0.53 & 8.990 & 5.66 \\
\hline 11 & 174.4 & 22.5 & 151.9 & 18.37 & 0.52 & 0.59 & 9.552 & 11.86 \\
\hline 12 & 135.6 & 22.5 & 113.1 & 18.83 & 0.49 & 0.44 & 9.227 & 11.36 \\
\hline 13 & 147.2 & 23 & 124.2 & 19.43 & 0.48 & 0.48 & 9.326 & 0.00 \\
\hline 14 & 163.9 & 23.2 & 140.7 & 19.9 & 0.5 & 0.54 & 9.950 & 7.41 \\
\hline 15 & 181.5 & 23.5 & 158 & 20.16 & 0.51 & 0.61 & 10.282 & 16.39 \\
\hline 16 & 176.8 & 24 & 152.8 & 20.42 & 0.54 & 0.59 & 11.027 & 8.47 \\
\hline 17 & 179.5 & 24.2 & 155.3 & 20.67 & 0.57 & 0.6 & 11.782 & 5.00 \\
\hline 18 & 159.7 & 24.6 & 135.1 & 20.94 & 0.57 & 0.52 & 11.936 & 9.62 \\
\hline 19 & 189.2 & 24.9 & 164.3 & 21.03 & 0.6 & 0.63 & 12.618 & 4.76 \\
\hline 20 & 150.9 & 25.3 & 125.6 & 21.21 & 0.57 & 0.48 & 12.090 & 18.75 \\
\hline \multicolumn{5}{|c|}{ Mean } & 0.445 & 0.460 & - & - \\
\hline
\end{tabular}

Time- Time (minutes)

T1 - Hot Side Temp $\left({ }^{\circ} \mathrm{C}\right)$

T2- Cold Side Temp $\left({ }^{\circ} \mathrm{C}\right)$

$\Delta \mathrm{T}$ - Temperature Difference
V- Voltage (Volts)

$\mathrm{I}_{A C T}$ - Actual Current

$\mathrm{I}_{T H E O}$ - Theoretical Current

P- Power (Watts) 
In order to validate the functionality of the device fabricated, a series of tests were taken. During the second trial, as shown in Table 2, the minimum voltage and current achieved was 5.8 volts and 0.125 ampere. The full power output generated was 21.24 watts having 29.5 volts and 0.72 amperes for its generated voltage and current. The margin of how narrow the percentage error for current shows lower value, at a score of 0.076 . It shows that the range of the highest and lowest percentage of error is closer. It also shows that the average percentage of error for current is closer to the theoretical current.

The calculated theoretical current at different temperature gradient was the basis of getting the relative error of the device's temperature. See Appendix C. All the variables needed for this study, such as the hot and cool side temperatures, the voltage, and the current are accumulated. The minimum voltage and current outputs are 5.8 volts and 0.125 ampere. The maximum voltage and current outputs are 29.5 volts and 0.72 ampere having the full power output of 21.24 watts. Based on the results obtained, the proponents did reach the minimum desired power to be generated in which the second trial was done indoor. Thus, creating a balanced environment with lesser wind and making a more stable heat inside the system of the oven and creating an approximately equal temperature in all of the TEG modules. The results also show that as the temperature difference increases, the voltage generated also increases.

Table 2. Actual output of TEG for Trial 2.

\begin{tabular}{|c|c|c|c|c|c|c|c|c|}
\hline TIME & T1 & T2 & $\Delta \mathbf{T}$ & $\mathbf{V}$ & IACT & ITHEO & $\mathbf{P}$ & Error (\%) \\
\hline 0 & 36.8 & 5.3 & 31.5 & 5.8 & 0.125 & 0.121 & 0.725 & 3.306 \\
\hline 1 & 100.8 & 8.7 & 92.1 & 7.85 & 0.363 & 0.355 & 2.8496 & 2.254 \\
\hline 2 & 155.7 & 10.4 & 145.3 & 12.3 & 0.5 & 0.56 & 6.15 & 10.714 \\
\hline 3 & 163.2 & 10.5 & 152.7 & 13.78 & 0.62 & 0.589 & 8.5436 & 5.263 \\
\hline 4 & 164.7 & 11.3 & 153.4 & 14.8 & 0.64 & 0.59 & 9.472 & 8.475 \\
\hline 5 & 183.7 & 12.7 & 171 & 15.5 & 0.65 & 0.66 & 10.075 & 1.515 \\
\hline 6 & 167.7 & 14.7 & 153 & 17.2 & 0.64 & 0.59 & 11.008 & 8.475 \\
\hline 7 & 157.3 & 23.1 & 134.2 & 18.6 & 0.6 & 0.52 & 11.16 & 15.385 \\
\hline 8 & 146.9 & 15.1 & 131.8 & 19.47 & 0.66 & 0.51 & 12.85 & 29.412 \\
\hline 9 & 153.1 & 15.9 & 137.2 & 20.2 & 0.65 & 0.53 & 13.13 & 22.642 \\
\hline 10 & 165.6 & 16.5 & 149.1 & 20.7 & 0.62 & 0.58 & 12.834 & 6.897 \\
\hline 11 & 169.1 & 16.5 & 152.6 & 21.2 & 0.68 & 0.59 & 14.416 & 15.254 \\
\hline 12 & 172.5 & 17.1 & 155.4 & 22.9 & 0.7 & 0.6 & 16.03 & 16.667 \\
\hline 13 & 172.4 & 16.4 & 156 & 23.6 & 0.72 & 0.6 & 16.992 & 20.000 \\
\hline 14 & 185.6 & 15.8 & 169.8 & 25 & 0.71 & 0.65 & 17.75 & 9.231 \\
\hline 15 & 186.3 & 15.3 & 171 & 25.7 & 0.68 & 0.65 & 17.476 & 4.615 \\
\hline 16 & 187 & 14.5 & 172.5 & 26.1 & 0.69 & 0.67 & 18.009 & 2.985 \\
\hline 17 & 186.7 & 13.6 & 173.1 & 26.9 & 0.72 & 0.67 & 19.368 & 7.463 \\
\hline 18 & 187.3 & 13 & 174.3 & 28 & 0.7 & 0.67 & 19.6 & 4.478 \\
\hline 19 & 188 & 12.5 & 175.5 & 28.7 & 0.69 & 0.68 & 19.803 & 1.471 \\
\hline 20 & 188.9 & 11.7 & 177.2 & 29.5 & 0.72 & 0.68 & 21.24 & 5.882 \\
\hline \multicolumn{5}{|c|}{ Mean } & 0.623 & 0.575 & - & - \\
\hline
\end{tabular}


Time- Time (minutes)

T1- Hot Side Temp $\left({ }^{\circ} \mathrm{C}\right)$

T2- Cold Side Temp $\left({ }^{\circ} \mathrm{C}\right)$

$\Delta \mathrm{T}$ - Temperature Difference
V- Voltage (Volts)

$\mathrm{I}_{A C T}$ - Actual Current

$\mathrm{I}_{T H E O^{-}}$Theoretical Current

P- Power (Watts)

The relationship between the temperature difference with the actual and theoretical currents are shown below in Figure 9 for the first trial and Figure 10 for the second trial.

Due to the sudden changes of the temperature reading, the graph of the theoretical current changes suddenly since the output of the current will be based on the actual temperature reading of each side of the TEG. This is the case that happened in the first trial of the device in which the device was placed outdoors where a strong gust of winds could affect the temperature. And one factor that could affect the temperature reading was the device that was used itself. Whether the device was calibrated properly or updated or not. Thus, the graph shows that the actual current reading was steady due to the stored heat and cool temperature on the housing of the TEG as compared to the theoretical current reading.

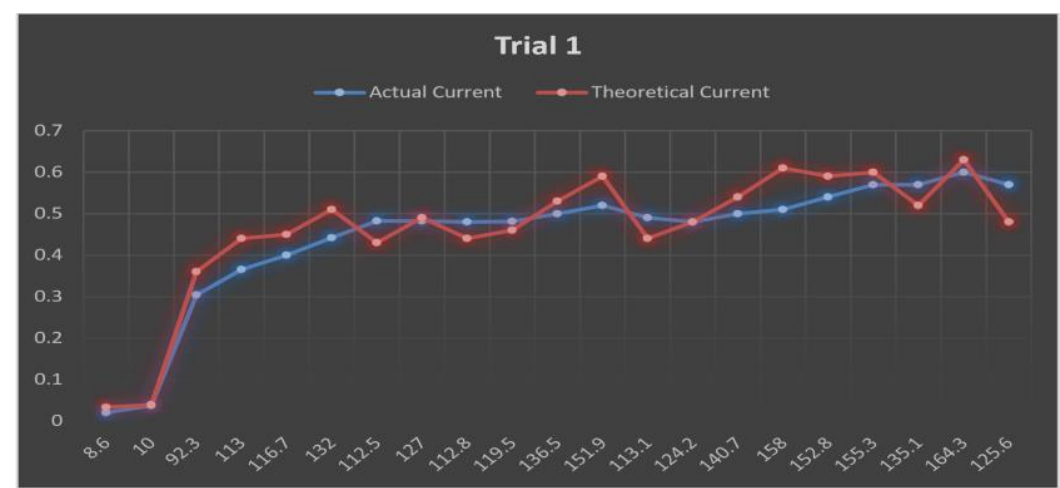

Figure 9. Temperature Difference, and Actual and Theoretical Currents relationship for Trial 1.

For the second trial of the device, the proponents had the chance to do the testing indoors where there are lesser to no gust of wind that could affect the temperature inside the system of the oven that could affect the output of the TEG. Thus, creating a more controlled environment to work on. The graph shows a relatively small difference between the actual and the theoretical current output of the TEG. Although the graph shows that the actual current output is greater than the theoretical output, it does not mean that the computation was not reliable. This is due to the infrared temperature sensor that was used by the proponents was calibrated a year ago that could differ the temperature reading of the instrument. But the actual current shows a steady output upon reaching the 20 -minute trial that the proponents conducted.

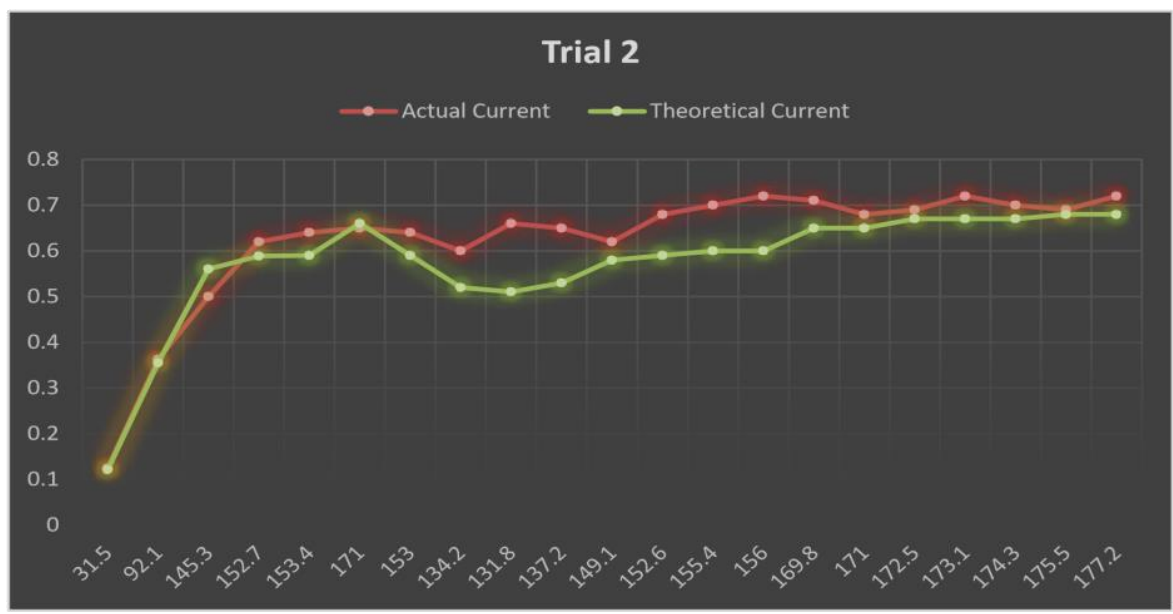

Figure 10. Temperature Difference, and Actual and Theoretical Currents relationship for Trial 2. 
Based on the result obtained, the proponents were able to design a generator by utilizing the waste heat of an oven. In a span of 15-20 mins., the output of the thermoelectric generator has reached the desired $20 \mathrm{~W}$ power output. And it can be said that it could power the lights as long as it reached the desired temperature to generate power with only a limited amount of resources but still able to maintain and could still increase the load of the TEG as time passes by. With the right materials and good maintenance, it could supply the desired beneficiaries for as long as the life span of the TEG.

\section{Conclusion}

Based on the observations and findings above, the researchers present the following conclusions:

1. The proponents concluded that with a short span of time using a small oven using only medium heat, it could achieve the minimum power output that was required.

2. The proponents concluded that each TEG could act as a resistor and could affect the power output due to the difference of power on each Peltier. Thus, each Peltier should have the same temperature with one another.

3. The proponents also concluded that the output of the thermoelectric generator will vary on the temperatures on the hot side and cold side but could still supply the minimum required a load of 20 Watts with the current design that the proponents used.

The proponents also present the following recommendations so that the future researchers will have an idea on what to improve next on the study:

1. Re-design the thermoelectric generator in order to maximize the thermoelectric generator.

2. Add thermoelectric generator modules to supply the water pump without relying on the external battery source.

3. Use supercapacitors for storing power in order to have more power to be inverted before supplying to an AC load.

\section{Acknowledgments}

The corresponding author would like to thank to the following: To the University of Mindanao Administration and Research Publication center, who never stop giving the support not just financially but also giving them ideas and morale support. To the proponents, Reymart A. Cepe, Neil S. Ricafort, Rosal Rhoda Jane G. Rosal, patient in conduct, collect and generate research idea. To the research coordinators, Engr. Rodrigo Pangantihon, Engr. Jethron Adtuon, for evaluating the capstone research of the researchers, to be prosperous and presentable. I would also like to acknowledge Dr. Chralito L. Canesares, Dean of the College to have an opportunity to present in the International paper presentation. To the friends, who helped in cheering up the researchers. And above all, to our Almighty God, who is always at the side of the corresponding author and researchers, leading them to the righteous path. Without Him, this research will not be possible.

\section{References}

Ahıska, R., \& Mamur, H. (2013). Design and implementation of a new portable thermoelectric generator for low geothermal temperatures. Retrieved from http://ieeexplore.ieee.org/document/6648807

Anatychuk, L. (2004). On the discovery of thermoelectricity by Volta. Journal of Thermoelectricity, vol. 2, 5-11.

Apertet, Y., Ouerdane, H., Goupil, C., \& Lecoeur, P. (October 2014). Influence of thermal environment on optimal working conditions of thermoelectric generators. Retrieved from http://www.researchgate.net/publication/265252436_Influence_of_thermal_enviro nment_on_optimal_working_conditions_of_thermoelectric_generators

Authority, M. D. (2015, April 30). Mindana sees an uptrend in renewable energy projects. Retrieved from http://www.minda.gov.ph/news/137-mindanao-sees-an-uptrend-in-renewable-energy-projects 
Balayo, V., Pamonag, J., \& Ybanez, J. (2015). Development of Waste Heat Recovery System Using Thermoelectric Generator.

Benson, D., \& Jayadev, T. (1980). Thermoelectric Energy Conversion, Economical ELectric Power from Low Grade Heat. Proceedings of the Third International Conference on Thermoelectric Energy Conversion (pp. 27-56). New York, NY: IEEE.

Capel, E., Ibrahim, T., \& Mohd Nor, N. (2013). Hybrid energy from exhaust system. Power Engineering and Optimization Conference (PEOCO), 2013 IEEE 7th International, IEEE.

Carlson, E., Strunz, K., \& Otis, B. (2010). A $20 \mathrm{mV}$ input boost converter with efficient digital control for thermoelectric energy harvesting. Retrieved from http://www.ieeexplore.ieee.org/document/5437494

Council, W. E. (2013). World Energy Resources 2013 Survey. London: World Energy Council. Retrieved from https://www.worldenergy.org/wp-content/uploads/2013/09/Complete_WER_2013_Survey.pdf

Czisch, G. (2006). Low cost but totally renewable electricity supply for a huge supply. Retrieved from https://transnational-renewables.org/Gregor_Czisch/projekte/LowCostEuropEISup_revised_ for_AKE_2006.pdf

Dewan, A., Ay, S., Karim, N., \& Beyenal. (2014). Alternative Power Sources for Remote Sensors: A Review. Journal of Power Sources, Elsevier.

Elarusi, A., Illendula, N., \& Fagehi, H. (2014). Performance Prediction of Commercial Thermoelectric Generator Modules using the Effective Material Properties. Retrieved from http://homepages.wmich.edu/ leehs/ME695/TEG\%20using\%20effective\%20material\%20propertie s.pdf

Elarusi, A., Illendula, N., \& Faggehi, H. (2010). Performance Prediction of Commercial Thermoelectric Generator Modules using the Effective Material Properties.

Energy, D. o. (2008, December 16). Republict act no. 9513 - An Act Promoting the Development, Utilization and Commercialization of Renewable Energy Resources and for other Purposes. Retrieved from http://www.officialgazette.gov.ph/2008/12/16/republic-act-no-9513/

Energy, D. o. (2008). Waste Heat Recovery: Technology and Opportunities in U.S. Industry. United States. Retrieved from https://www1.eere.energy.gov/manufacturing/intensiveprocesses/pdfs/waste_heat_recovery.pdf

Feulner, P., Dr. Vlaskos, I., \& Dr. Michos, C. (2014). Waste Heat Recovery in Marine Propulsion Systems. SNAME. Athens, Greece. Retrieved from https://higherlogicdownload.s3.amazonaws.com/SNAME/e10ad46f-35fe-4b7d-a4cf3da678bacc3f/ UploadedImages/SNAME-20\%2002\%202014_Waste_Heat_Recovery_in_Marine_Propulsion_ Systems-Final.pdf

G. Min, D. M. (2004). Thermoelectric figure-of-merit under large temperature differences. Journal of Physics D: Applied Physics, vol. 37, pp. 1301-1304.

Gould, C., Shammas, N., Grainger, S., \& Taylor, I. (May 11-14, 2008). A comprehensive review of thermoelectric technology, micro-electrical and power generation properties. 26th International Conference on Microelectronics.

Gusev, V., Pustovalov, A., Rybkin, N., Anatychuk, L., Demchuk, B., \& Ludchak, I. (2011). Milliwattpower radioisotope thermoleectric generator (RTG) based on plutonium-238. Journal of Electronic Materials.

Henderson, J. (1979). Analysis of a Heat Exchanger- Thermoelectric Generator System. Proceedings of the 14th Intersociety Energy Conversion Engineering Conference. Boston.

Hidden Curriculum. (2014, August). Retrieved from http://edglossary.org/hidden-curriculum

Hsu, C., Yao, D., Ye, K., \& Yu, B. (2010). Renewable energy of waste heat recovery system for automobiles.

IEA. (2012). Renewable Energy: Coming of Age. The Journal of the International Energy Agency.

IPCC. (2011). Renewable Energy Sources and Climate Change Mitigation. Special Report of the Intergovernmental Panel on Climate Change.

J. Chen, Z. Y. (1996). The influence of Thomson effect on the maximum power output and maximum effciency of a thermoelectric generator. Journal of Applied Physics, vol. 79, no. 11, p. 8823.

Jacobson, M. Z., \& Delucchi, M. A. (2010). Providing all global energy with wind, water, and solar power, Part I: Technologies, energy resources, quantities and areas of infrastructure, and materials. 
Jeevitha, S., Rajan, S. E., \& Rakesh, T. (2009). Performance Analysis of High Gain DC-DC Boost Converter for Thermoelectric Power Generation System. India.

Kim, S., \& al, e. (2011). Thermoelectric power generation system for future hybrid vehicles using hot exhaust gas. Journal of Electronic Materials.

Lazard, M. (2009). "Heat Transfer in Thermoelectricity: Modelling, Optimization and Design. 7th IASME/WSEAS International International Conference on Heat Transfer, Thermal Engineering, (pp. 129-134).

Lee, M., Joseph, R., Jet, T., \& Qingyu, A. (2016). Design of Stand-alone Thermoelectric Power Generation System fo Marine Engine Exhaust System. IEEE.

Lemley, L. (1980). A Radiation Thermoelectric Power Converter. Proceedings of the Third Conference on Thermoelectric Energy Conversion (pp. 20-26). New York, NY: IEEE.

Li, G., Shrotriya, V., Huang, J., Yao, Y., Moriarty, T., Emery, K., \& Yang, Y. (2005). High-efficiency Solution Processable Polymer Photovoltaic Cells by Self-organization of Polymer Blends. Nature Materials, 864-868.

Lorenz, R. (2003). Subsurface ambient thermoelectric power for moles and penetrators. IEEE Aerospace Conference. Big Sky, MT, Citeseer.

McEnaney, K., Kraemer, D., Chen, Z., \& Ren, G. (2011). Modeling of concentrating solar theroelectric generators. Journal of Applied Physics.

Mueller, P. (2007). The Abundance of Fossil Fuels: Why We Will Not Run Out of Fossil Fuels. The Global Warming Policy Foundation.

Nolas, G., Sharp, J., \& Goldsmid, H. (2001). Thermoelectrics. Heidelberg, Germany: Springer.

Nuwayhid, R., Shihadeh, A., \& Ghaddar, N. (2005). Development and testing of a domestic woodstove thermoelectric generator with natural convection cooling.

Patil, D. \& Arakerimath, R.R. (2013). A Review of Thermoelectric Generator for Waste Heat Recovery from Engine Exhaust. International Journal of Research in Aeronautical and Mechanical Engineering, 1-9.

Phillip, N., Maganga, O., Burnham, K., Dunn, J., Rouaud, C., Ellis, M., \& Robinson, S. (2012). Modelling and Simulation of a Thermoelectric Generator for Waste Heat Energy Recovery in Low Carbon Vehicles. 2nd International Symposium on Environment Friendly Energies and Applications (EFEA).

Pimentel, D., Herz, M., Glickstein, M., Zimmerman, M., Allen, R., Becker, K., . . Seidel, T. (December 2002). Renewable Energy: Current and Potential Issues. BioScience, 52.

Project, T. C. (2016, February 3). Follow the Leader: How 11 Countries are Shifting to Renewable Energy. Retrieved December 21, 2016, from https://www.climaterealityproject.org/blog/followleader-how-11-countries-are-shifting-renewable-energy

Qiu, K., \& Hayden, A. (2008). Development of a Thermoelectric Self-powered Residential Heating System. Journal of Power Sources.

R. S. Muller, T. I. (2002). Device Electronics for Integrated Circuits. In Device Electronics for Integrated Circuits.

Rais, I., Orgerie, A., Lefevre, L., \& Benoit, A. (2016). An Analysis of the Feasibility of Energy Harvesting with Thermoelectric Generators on Petascale and Exascale Systems. High Performance Computing and Simulation (HPCS), 2016 International Conference on.

Ravindra, S., Huesgen, T., Kroener, M., \& Woias, P. (2011). A Self-sustaining Micro Thermomechanicpyroelectric Generator. Applied Physics Letter.

Rinalde, G., Juanico, L., Taglialavore, E., Gortari, S., \& Molina, M. (2010). Rinalde, G.F., Juanico, L.E., Taglialavore, E.Development of Thermoelectric Generators for Electrification of Isolated Rural Homes. International Journal of Hydrogen Energy.

Ritz, F., \& Peterson, C. (2004). Multi-mission radioisotope thermoelectric generator (MMRTG) program overview. Aerospace Conference Proceedings IEEE.

Rivadulla, F., Murias, B., Capeáns, G., Lopez, P., Ferro, E., \& Cabello, A. (2016). Design for Maximum Power Transfer Efficiency of Thermoelectric Generators using Mixed Mode Simulations. 17th International Conference on Thermal, Mechanical and Multi-Physics Simulation and Experiments in Microelectronics and Microsystems.

Rowe, D. (2006). Review thermoelectric waste heat recovery as a renewable energy source. 
Schneider, S., Easterling, W., \& Mearms, L. (2000). Adaptation: Sensitivity to natural variability, agent assumptions, and dynamic climatic changes.

Stanciu, V., Barsan, I., Hantila, F., Maricaru, M., \& Stanculescu, M. (2013). Pulsed operation analysis of the thermoelectric generators used in space applications. Advanced Topics in Electrical Engineering (ATEE), 2013 8th International Symposium on, IEEE.

Stecanella, P., Faria, M., Domingues, E., Gomes, P., \& Calixto, W. (2015). Electricity Generation Using Thermoelectric Generator - TEG. IEEE.

Stevens, J. (2000). Heat Transfer and Thermoelectric Dsign Considerations for a Ground-source Thermoelectric Generator. 18th International Conference on Thermoelectrics.

Synder, G., \& Toberer, E. (2008). Complex Thermoelectric Materials. Nature Materials, 778-781.

Vining, C. (2009). An inconvenient truth about thermoelectrics. Nature Materials.

Weera, S. (2014). Analytical Performance Evaluation of Thermoelectric Modules Using Effective Material Properties.

Wen, C.-Y. D.-D. (2011). Experimental investigation and numerical analysis for one-stage thermoelectric cooler considering Thomson effect. International Journal of Heat and Mass Transfer, vol. 54, pp. 4875-4884.

Whitehouse, D. (2013). The Global Warming Standstill. The Global Warming Policy Foundation.

Wu, C. (1996). Analysis of Waste-heat Thermoelectric Power Generators. Applied Thermal Engineering, 63-69.

Zhou, Y., Paul, S., \& Bhunia, S. (2008). Harvesting Wasted Heat in a Microprocessor Using Thermoelectric Generators: Modeling, Analysis and Measurement. Design, Automation and Test in. Europe. 